\title{
Unexpected Behavior of the Hydrogen Oxidation Reaction on Palladium in Alkaline Solution: A Feasible Kinetic Explanation
}

\author{
María A. Montero, María R. Gennero de Chialvo, and Abel C. Chialvo ${ }^{* * z}$ \\ Instituto de Química Aplicada del Litoral, IQAL (UNL-CONICET), Programa de Electroquímica Aplicada e Ingeniería \\ Electroquímica, PRELINE (FIQ-UNL), Santa Fe 3000, Argentina
}

\begin{abstract}
The hydrogen oxidation reaction was studied on a thin film palladium electrode supported on a gold substrate in alkaline solution. The hydrogen absorption process was analyzed by open circuit potential transient and the current - overpotential dependences were obtained by chronoamperometry at different rotation rates in a solution saturated with hydrogen. The results obtained show an unexpected profile at low overpotentials, where current decreases as rotation rate increases. A kinetic mechanism was proposed to interpret this behavior and the corresponding equations were derived. They were used to correlate the results, with a good agreement between the experimental and fitted curves.

(C) The Author(s) 2018. Published by ECS. This is an open access article distributed under the terms of the Creative Commons Attribution 4.0 License (CC BY, http://creativecommons.org/licenses/by/4.0/), which permits unrestricted reuse of the work in any medium, provided the original work is properly cited. [DOI: 10.1149/2.0111815jes]

(cc) BY
\end{abstract}

Manuscript submitted June 25, 2018; revised manuscript received August 16, 2018. Published September 12, 2018. This paper is part of the JES Focus Issue on Electrocatalysis - In Honor of Radoslav Adzic.

Numerous works have been published related to the study of the hydrogen oxidation reaction (hor) due to its application as the anodic reaction in proton exchange membrane fuel cells. However, fundamental kinetic studies were mainly carried out on platinum group metals. ${ }^{1-5}$ Among this group, the case of palladium has the peculiarity that hydrogen is not only adsorbed $\left(\mathrm{H}_{\mathrm{ad}}\right)$, but also is absorbed $\left(\mathrm{H}_{\mathrm{ab}}\right)$ in the metallic matrix. Depending on hydrogen pressure during the absorption process, two phases can be found, $\alpha \mathrm{Pd}-\mathrm{H}$ or $\beta \mathrm{Pd}-\mathrm{H},{ }^{6-8}$ as well as a phase transition between them. Absorption is independent of whether palladium is in contact with molecular hydrogen in gas phase or dissolved in an electrolytic solution. ${ }^{9}$ Therefore, the presence of $\mathrm{H}_{\mathrm{ab}}$ influences the kinetics of the hydrogen electrode reaction in their both directions, the cathodic hydrogen evolution reaction (her) and the hor, although it was not considered in most of the studies, where slow potentiodynamic sweeps were used. ${ }^{10-15}$ Otherwise a work carried out on steady state in acid solutions, employing chronoamperometry, showed that the her is verified on $\beta \mathrm{Pd}-\mathrm{H}$, while the hor involves both phases. ${ }^{16}$ $\beta \mathrm{Pd}-\mathrm{H}$ is stable at low $(\eta<0.05 \mathrm{~V})$ and $\alpha \mathrm{Pd}-\mathrm{H}$ at high overpotentials, being $\beta \mathrm{Pd}-\mathrm{H}$ better electrocatalyst. ${ }^{16}$ All these results indicates that attention should be paid to the role played by the absorption phenomena on the electrodic processes. In this sense, there are several works devoted to the understanding of the dynamics of the electrochemical hydrogen absorption in the Pd/electrolyte interface. It can be mentioned the pioneering works of S. Schuldiner ${ }^{17}$ and G.W. Castellan ${ }^{18}$ as well as the more recent studies due to A. Lasia, ${ }^{19-23}$ where the mechanisms of hydrogen insertion in the Pd matrix starting from the proton electroreduction were discussed. ${ }^{19-26}$ The indirect mechanism postulates that proton is reduced to adsorbed hydrogen $\left(\mathrm{H}_{\mathrm{ad}}\right)$ through the Volmer step and then it is absorbed in palladium. ${ }^{23,24}$ On the other hand, the direct mechanism proposes the reduction of proton to a subsurface absorbed hydrogen. ${ }^{25,26}$ However, the processes that would take place when a Pd electrode is immersed in an electrolytic solution containing molecular hydrogen have not been analyzed yet and even less considered for the interpretation of the hydrogen oxidation on $\mathrm{Pd}$ in alkaline solution. The influence should be particularly important in this solution, where the kinetics of the hor is in general slower than in acid and therefore absorption processes could become more significant.

The few works that studied the hydrogen oxidation in alkaline solutions showed that palladium presents a significantly lower electrocatalytic activity compared with the values corresponding to other noble metals (Rh, Ir) in similar experimental conditions. ${ }^{27,28}$ These

\footnotetext{
*Electrochemical Society Member.
}

${ }^{\text {z} E-m a i l: ~ a c h i a l v o @ ~ f i q . u n l . e d u . a r ~}$ results would indicate that the kinetic mechanism involved in the reaction is influenced by the concentration of the absorbed hydrogen. In this context, the present work deals with the kinetic study of the hydrogen oxidation reaction on a Pd electrode in alkaline solution starting with the analysis of the current - potential curves in steady state, considering the absorption process that goes along with the reaction.

\section{Experimental}

Electrode preparation.-The palladium electrode was prepared via sputtering on a gold substrate from a Pd target in an argon atmosphere (0.1 mbar), using a sputter coater Emitech K500X, operated at $40 \mathrm{~mA}$ during 4 minutes. The gold substrate was previously mirror polished and subjected to ultrasonic cleaning in ultra-pure water for 5 minutes and then it was voltammetrically characterized to ensure a clean and reproducible deposition surface.

Electrochemical measurements.-All the electrochemical experiments were carried out in a three electrode cell specially built for the use of a rotating electrode and with a particular design of the gas saturator. The electrolyte solutions used were $0.1 \mathrm{M} \mathrm{NaOH}$ and $0.5 \mathrm{M}$ $\mathrm{H}_{2} \mathrm{SO}_{4}$. The reference electrode was a hydrogen bubble electrode in the same solution (RHE), located inside a Luggin-Haber capillary tube. The counter electrode was a palladium wire of high area, located in a separate compartment in order to avoid contamination. Ultra pure water (PureLab, Elga LabWater, resistivity 18.2 M $\Omega$ ) was employed for cell rinsing and solution preparation. The working electrode was mounted in a Teflon holder, with a geometric exposed area of $0.07 \mathrm{~cm}^{2}$ and connected to a rotating disc device. The electrode was electrochemically characterized via cyclic voltammetry between $0.05 \mathrm{~V}$ and $1.35 \mathrm{~V}$ at $0.1 \mathrm{~V} \mathrm{~s}^{-1}$ under nitrogen atmosphere in $0.5 \mathrm{M}$ $\mathrm{H}_{2} \mathrm{SO}_{4}$ solution. All experiments were carried out at room temperature (295 K).

The kinetic study of the hydrogen oxidation reaction was carried out in a $0.1 \mathrm{M} \mathrm{NaOH}$ solution, ensuring a continuous saturation of the electrolyte with molecular hydrogen. The electrocatalytic activity of the Pd electrode was evaluated through the current $(I)$ - overpotential $(\eta)$ response at different rotation rates in the range $900 \leq \omega / \mathrm{rpm}$ $\leq 4900$. A potential program was applied for the evaluation of the reaction on steady state, which initiated with a $3 \mathrm{~s}$ step at $0.0 \mathrm{~V}$, followed by a $90 \mathrm{~s}$ step at the desired overpotential value. In this last period, readings of the current value were made each $0.1 \mathrm{~s}$ and the mean value of the current data measured in the last $2 \mathrm{~s}$ was assigned to the step overpotential. Then the program was repeated for each $\eta$ value, 


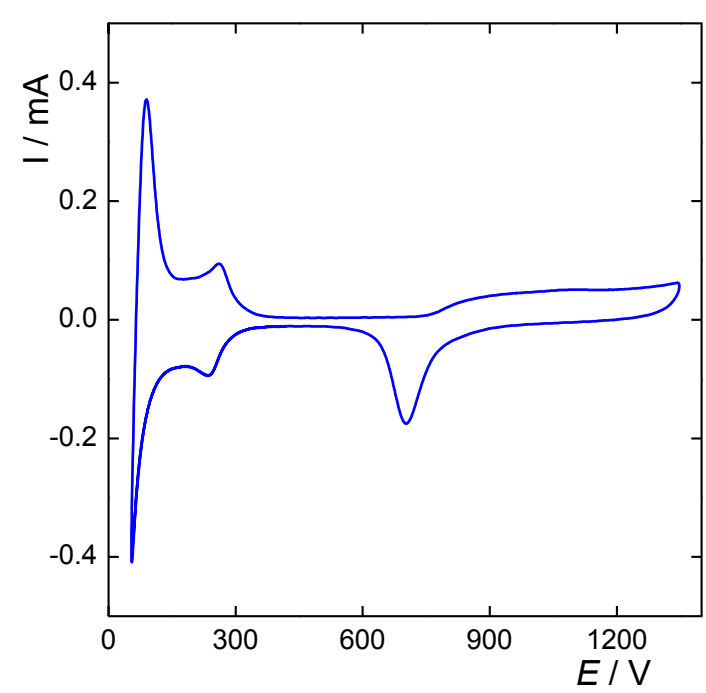

Figure 1. Cyclic voltammogram of the Pd thin film electrode recorded at $0.1 \mathrm{~V} \mathrm{~s}^{-1}$ in $0.5 \mathrm{M} \mathrm{H}_{2} \mathrm{SO}_{4}$.

which was varied in the range $0.0 \leq \eta / \mathrm{V} \leq 0.7$. Kinetic measurements of the hor was also carried out through the application of a slow potentiodynamic sweep run at $10 \mathrm{mV} \mathrm{s}^{-1}$ at the same overpotentials range and rotation rates.

Measurements of the open circuit potential (OCP) was also carried out. The experiments were carried out in alkaline $(0.1 \mathrm{M} \mathrm{NaOH})$ and acid $\left(0.5 \mathrm{M} \mathrm{H}_{2} \mathrm{SO}_{4}\right)$ solutions saturated with molecular hydrogen. The electrode was polarized at $0.8 \mathrm{~V}$ during $2 \mathrm{~s}$, then the circuit was opened and the potential dependence on time was registered.

\section{Results}

Electrode area.-The real area of the Pd electrode was evaluated from the oxide electroreduction charge of the voltammetric profile in acid solution, following the procedure given elsewhere. ${ }^{29}$ Fig. 1 shows the voltammogram recorded in $0.5 \mathrm{M} \mathrm{H}_{2} \mathrm{SO}_{4}$ in the potential range $0.05 \leq E / \mathrm{V} \leq 1.35$. The charge obtained by integration of the oxide electroreduction peak was $178 \mu \mathrm{C}$. As the charge per unit area corresponding to the upper potential limit $1.35 \mathrm{~V}$ is $353 \mu \mathrm{C} \mathrm{cm}^{-2},{ }^{29}$ the resulting real area was $0.504 \mathrm{~cm}^{-2}$.

Open circuit potential.- - Taking into account the importance of the hydrogen absorption in the Pd film and in order to evaluate the time needed to reach equilibrium with hydrogen in solution, the open circuit potential (OCP) decay was analyzed. After the polarization of the electrode at $0.8 \mathrm{~V}$ during $2 \mathrm{~s}$ in the solution saturated with $\mathrm{H}_{2}$, the circuit was opened and the transient potential dependence was registered (Fig. 2). The continuous line corresponds to the acid solution $\left(0.5 \mathrm{M} \mathrm{H}_{2} \mathrm{SO}_{4}\right)$ while the dashed line depicted the response in the alkaline medium $(0.1 \mathrm{M} \mathrm{NaOH})$. The fast decrease of the OCP registered at the beginning is related to the evolution of the system toward equilibrium ( $E=0.0 \mathrm{vs}$. RHE) together with the hydrogen absorption in the form $\alpha \mathrm{Pd}-\mathrm{H}$. However, it can be observed at approximately $10 \mathrm{~s}$ the appearance of a plateau around $0.06 \mathrm{~V}$, which corresponds to the transition to the $\beta \mathrm{Pd}-\mathrm{H}$ phase. ${ }^{30}$ As the gold substrate is impermeable to hydrogen, palladium behaves as a limited volume electrode and quickly $(\sim 12 \mathrm{~s})$ equilibrates its concentration with that of the molecular hydrogen at the surface, which at open circuit corresponds to saturation at atmospheric pressure.

It should be noticed that although hydrogen diffusion inside the palladium matrix is independent of the electrolytic solution in which it is immersed, the inlet through the electrolyte/metal interphase is determined by the nature of the electrolyte, as it can be derived from

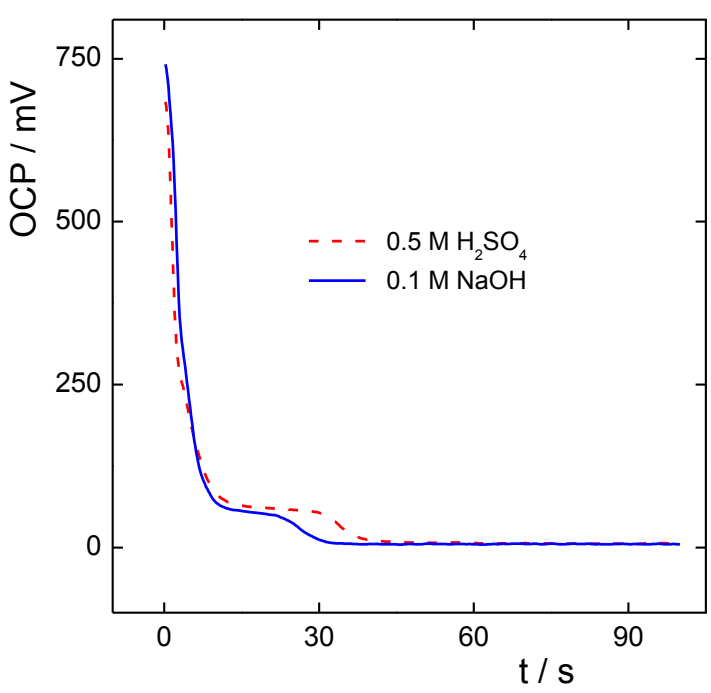

Figure 2. Open circuit potential transients on Pd thin film electrode recorded in the hydrogen saturated $(1 \mathrm{~atm})$ solutions indicated in the figure.

the difference in the time needed to saturate the metal matrix with $\beta \mathrm{Pd}-\mathrm{H}$, being $40 \%$ less in alkaline than in acid solution.

Voltammetric response.-Fig. 3 shows the current - overpotential profiles corresponding to the application of a voltammetric sweep run at $10 \mathrm{mV} \mathrm{s}^{-1}$ between $-0.05 \leq \eta / \mathrm{V} \leq 0.70$ in $0.1 \mathrm{M} \mathrm{NaOH}$ solution saturated with hydrogen gas at atmospheric pressure. The potentiodynamic sweeps were carried out at five different rotation rates $(900,1600,2500,3600$ and $4900 \mathrm{rpm})$. In the anodic sweep it can be observed that current passes through a maximum, that corresponds to the oxidation of the absorbed hydrogen contained in the limited volume of the palladium thin film electrode. After that, the limiting diffusion current is reached. Moreover, a peak with positive current values is depicted in the cathodic sweep. The voltammetric current - potential response shows a lower electrocatalytic activity of Pd for the hydrogen oxidation reaction compared to $\mathrm{Ir}^{27}$ and $\mathrm{Rh}^{28}$ in similar experimental conditions.

Steady state measurements. - The study of the hydrogen oxidation reaction on steady state on $\mathrm{Pd}$ in $0.1 \mathrm{M} \mathrm{NaOH}$ solution was

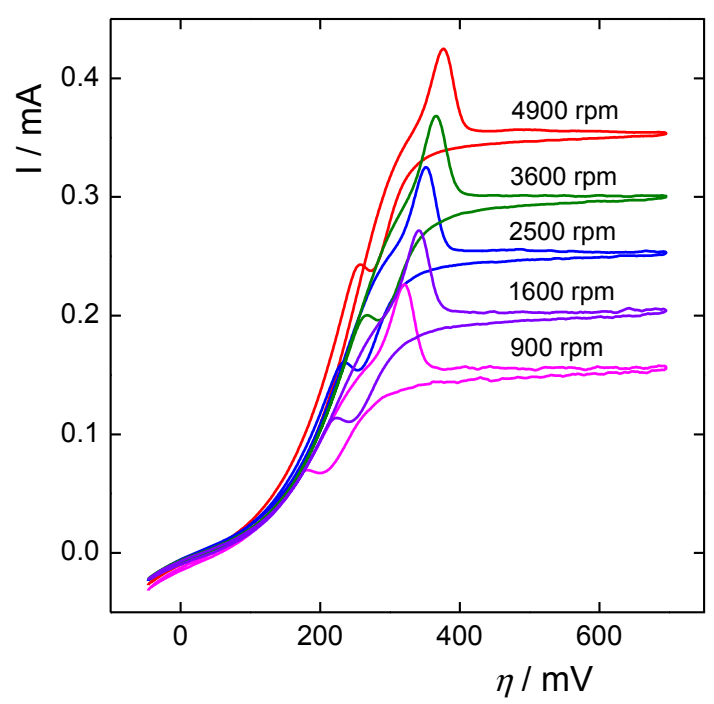

Figure 3. $I(\eta)$ dependences obtained by voltammetric sweep run at $0.01 \mathrm{~V} \mathrm{~s}^{-1}$ for the hydrogen oxidation on Pd thin film electrode in hydrogen saturated $0.1 \mathrm{M} \mathrm{NaOH}$ solution at $22^{\circ} \mathrm{C}$. Rotation rates indicated in the figure. 


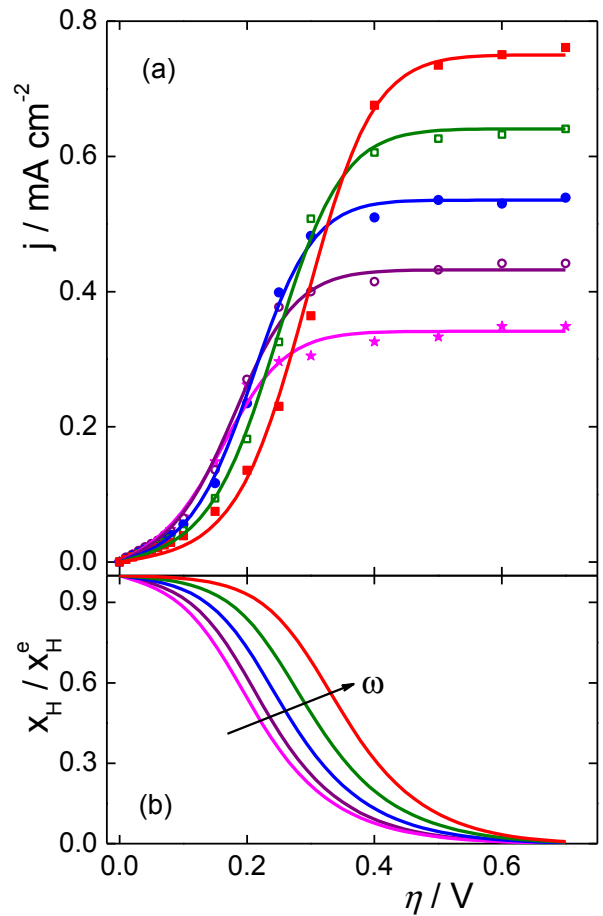

Figure 4. (a) Measured (symbols) and fitted (lines) $j(\eta)$ dependences on steady state for the hydrogen oxidation on Pd thin film electrode in hydrogen saturated $0.1 \mathrm{M} \mathrm{NaOH}$ solution at $22^{\circ} \mathrm{C}$. Fitted curves were obtained using

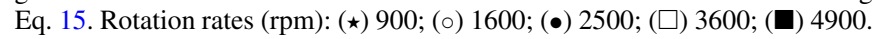
(b) $x_{H} / x_{H}^{e}(\eta)$ dependences obtained using Eq. 10 at the different rotation rates.

carried out by the application of a chronoamperometric technique at different rotation rates $(900,1600,2500,3600$ and $4900 \mathrm{rpm})$ in the overpotentials range $0.0 \leq \eta / \mathrm{V} \leq 0.70$. The resulting current overpotential dependences are shown in Fig. 4. It can be observed a markedly different behavior with respect to those corresponding to other metal electrodes. The common polarization plots in both, acid and alkaline solutions, always show at constant overpotential an increment in current as rotation rate increases. In the present case it can be observed the opposite behavior for $\eta<0.20 \mathrm{~V}$, where the current decreases as $\omega$ increases. Then there is a transition region between $0.20 \mathrm{~V}$ and $0.40 \mathrm{~V}$ where the order changes and finally, for $\eta>0.40 \mathrm{~V}$ the usual variation of current on rotation rate at constant overpotential is achieved. As this behavior was never observed before, numerous measurements with different electrodes, using a random sequence of overpotentials, were carried out. In all cases it was obtained the same response.

\section{Discussion}

The hydrogen oxidation reaction was studied on a palladium thin film deposited on a gold substrate in $0.1 \mathrm{M} \mathrm{NaOH}$ solution. The resulting current - overpotential dependences in steady state are notoriously different to those observed previously in acid solution, ${ }^{16}$ where it could be clearly appreciated the transition between the $\alpha \mathrm{Pd}-\mathrm{H}$ and $\beta \mathrm{Pd}-\mathrm{H}$ phases in the overpotential range $0.04 \leq \eta / \mathrm{V} \leq 0.10$. Moreover, it can be also observed a markedly different behavior with respect to other noble metal electrodes $\left(\mathrm{Ir},{ }^{27} \mathrm{Rh}\right)^{28}$ in alkaline solution, which polarization plots show in the whole range of potentials a monotonic increase in current as rotation rate increases. On the contrary, the hor on Pd shows for overpotentials less than $0.20 \mathrm{~V}$ a decrease in current as $\omega$ increases. The immediate consequence of this result is that the Tafel-Heyrovsky-Volmer mechanism, which usually interprets the reaction on noble metals, cannot explain the kinetics on Pd in alkaline solution. Thus, in order to analyze appropriately this behavior, it should be taken into account three important aspects that arise from de experimental measurements. One of them is related to the notoriously slow reaction rate at low overpotentials. For $\eta<0.15 \mathrm{~V}$ it is not observed any signal of a limiting kinetic current due to the Tafel step. ${ }^{4,5}$ As it is a purely chemical step, its contribution should be noticed at low $\eta$ values, while the reaction rate of the Heyrovsky step increases exponentially with potential and displaces completely any Tafel contribution. ${ }^{4,5}$ A second aspect is related to the presence of an overpotential region where current decreases with the increase of the rotation rate, as it was already stated. Finally, the third aspect is related to the hydrogen absorption in the Pd electrode, which reaches quickly the equilibrium condition, as it can be derived from the open circuit potential measurement.

In order to advance in the understanding of the phenomena that take place during the hydrogen oxidation reaction in steady state on $\mathrm{Pd}$ in alkaline solution and the description of the dependence of current density on overpotential, a kinetic mechanism compatible with the experimental evidences is developed. Considering that the hor is verified at a reaction rate $(v)$, with a superficial concentration of the molecular hydrogen $\left(C_{H_{2}}^{s}\right)$, obviously less than that of the bulk solution $\left(C_{H_{2}}^{o}\right)$, a surface coverage of the adsorbed hydrogen $\left(\theta_{H}\right)$ and a concentration of the absorbed hydrogen in the Pd subsurface $\left(x_{H}\right)$, the steady state condition implies that $C_{H_{2}}^{s}, \theta_{H}$ and $x_{H}$ are invariant on time and that the hydrogen concentration inside palladium is uniform. This condition is fulfilled because the Pd electrode consists in a thin film obtained by sputtering on an impermeable gold substrate, which quickly absorb hydrogen as it was demonstrated by the OCP experiment. Moreover, the absence of an indication of the participation of the Tafel step at low overpotentials, where the noble metals exhibit a predominance of the Tafel-Volmer pathway, ${ }^{27,28}$ leads to the conclusion that the Tafel step can be considered negligible. Therefore, on steady state the dependences $\theta_{H}\left(x_{H}\right)$ and $C_{H_{2}}^{s}\left(x_{H}\right)$ must be at equilibrium. It should be bear in mind that these considerations do not include the processes related to charge transfer, where the surface coverage of the reaction intermediate $\left(\mathrm{H}_{\mathrm{ad}}\right)$ depends on the hydrogen absorption. On the basis of this analysis, a kinetic mechanism is proposed, which must be able to describe the experimental current density - overpotential dependences. It involves the molecular hydrogen in a direct absorption in the Pd subsurface (step 1),

$$
H_{2} \rightleftharpoons 2 H_{a b}
$$

as well as in the electroadsorption reaction (Heyrovsky step),

$$
\mathrm{H}_{2}+\mathrm{OH}^{-}+\mathrm{S} \rightleftharpoons \mathrm{H}_{a d}+\mathrm{H}_{2} \mathrm{O}+e^{-}
$$

In order that the steady state condition could be fulfilled, the following step must be accomplished,

$$
H_{a b}+S \rightleftharpoons H_{a d}
$$

and finally mechanism is completed with the oxidation of the reaction intermediate through the Volmer step,

$$
\mathrm{H}_{a d}+\mathrm{OH}^{-} \rightleftharpoons \mathrm{H}_{2} \mathrm{O}+e^{-}+\mathrm{S}
$$

It should be important to note that the concentration of $\mathrm{H}_{\mathrm{ab}}$ in the $\mathrm{Pd}$ subsurface is not necessarily equal to that in the Pd matrix.

From the analysis given above, in steady state the steps (1) and (3) are at equilibrium. They represent a splitting of the Tafel step, although this implies kinetic consequences that will be analyzed later. The expressions of the reaction rates of the steps, on terms of the corresponding equilibrium reaction rates, are (see Appendix),

$$
\begin{gathered}
v_{1}=v_{1}^{e}\left[\frac{C_{H_{2}}^{s}}{C_{H_{2}}^{o}}-\frac{x_{H}^{2}}{x_{H}^{e}}\right] \\
v_{2}=v_{2}^{e}\left[\frac{C_{H_{2}}^{s}}{C_{H_{2}}^{o}} \frac{\left(1-\theta_{H}\right)}{\left(1-\theta_{H}^{e}\right)} e^{\alpha f \eta}-\frac{\theta_{H}}{\theta_{H}^{e}} e^{-(1-\alpha) f \eta}\right]
\end{gathered}
$$




$\begin{aligned} & \text { Table I. Kinetic parameters obtained from the fitting of the } \\
& \text { experimental } \boldsymbol{j}(\boldsymbol{\eta}) \text { dependences in steady state } \\
& \text { Eq. 15. }\end{aligned}$
\begin{tabular}{lllll} 
(Fig. 4$)$ & with \\
$\omega, \mathrm{rpm}$ & $v_{2}^{e}, \mathrm{~mol} \mathrm{~cm}^{-2} \mathrm{~s}^{-1}$ & $v_{4}^{e}, \mathrm{~mol} \mathrm{~cm}^{-2} \mathrm{~s}^{-1}$ & $\theta_{H}^{e}$ & $\alpha$ \\
\hline 900 & $1.1910^{-12}$ & $1.3110^{-10}$ & 0.27 & 0.516 \\
1600 & $1.1910^{-12}$ & $1.1210^{-10}$ & 0.27 & 0.519 \\
2500 & $1.1910^{-12}$ & $8.8710^{-11}$ & 0.27 & 0.502 \\
3600 & $9.9210^{-13}$ & $5.7710^{-11}$ & 0.27 & 0.49 \\
4900 & $9.9210^{-13}$ & $2.5010^{-11}$ & 0.27 & 0.49 \\
Average & $1.1110^{-12}$ & $8.2910^{-11}$ & 0.27 & 0.503
\end{tabular}

$$
\begin{gathered}
v_{3}=v_{3}^{e}\left[\frac{x_{H}}{x_{H}^{e}} \frac{\left(1-\theta_{H}\right)}{\left(1-\theta_{H}^{e}\right)}-\frac{\theta_{H}}{\theta_{H}^{e}}\right] \\
v_{4}=v_{4}^{e}\left[\frac{\theta_{H}}{\theta_{H}^{e}} e^{\alpha f \eta}-\frac{\left(1-\theta_{H}\right)}{\left(1-\theta_{H}^{e}\right)} e^{-(1-\alpha) f \eta}\right]
\end{gathered}
$$

The relationship between the concentrations $C_{\mathrm{H}_{2}}^{s} / \mathrm{C}_{\mathrm{H}_{2}}^{o}$ in steady state can be easily related to the corresponding relationship between the current density $(j)$ and the limiting diffusion current density $\left(j_{L}\right)$,

$$
\frac{C_{H_{2}}^{s}}{C_{H_{2}}^{o}}=1-\frac{j}{j_{L}}
$$

As the steps (1) and (3) are at equilibrium, the substitution of Eq. 9 into Eq. 5 gives,

$$
\frac{x_{H}}{x_{H}^{e}}=\frac{C_{H_{2}}^{s}{ }^{1 / 2}}{C_{H_{2}}^{o}{ }^{1 / 2}}=\frac{\left(j_{L}-j\right)^{1 / 2}}{j_{L}{ }^{1 / 2}}
$$

Moreover, substituting Eq. 10 into Eq. 7 and operating results,

$$
\begin{aligned}
\frac{\theta_{H}}{\theta_{H}^{e}} & =\frac{\left(j_{L}-j\right)^{1 / 2}}{\left(j_{L}-j\right)^{1 / 2} \theta_{H}^{e}+j_{L}^{1 / 2}\left(1-\theta_{H}^{e}\right)} \\
\frac{\left(1-\theta_{H}\right)}{\left(1-\theta_{H}^{e}\right)} & =\frac{j_{L}^{1 / 2}}{\left(j_{L}-j\right)^{1 / 2} \theta_{H}^{e}+j_{L}^{1 / 2}\left(1-\theta_{H}^{e}\right)}
\end{aligned}
$$

Taking into account that the global reaction in alkaline solution is,

$$
\mathrm{H}_{2}+2 \mathrm{OH}^{-} \rightleftharpoons 2 \mathrm{H}_{2} \mathrm{O}+2 e^{-}
$$

the relationship between the current density and the reaction rate is $j=2 \mathrm{~F} v$. In steady state the following expression is straightforward,

$$
j=2 F V=F\left(v_{2}+v_{4}\right)
$$

Substituting Eqs. 9-12 into Eqs. 6 and 8 and then these equations into Eq. 14, the dependence of the current density on overpotential for the hydrogen oxidation on Pd in alkaline solution is obtained,



The experimental $j(\eta)$ curves were correlated with Eq. 15 through the application of a nonlinear least squares regression method, using the software Micromath Scientific 3.0. Each polarization curve of a given rotation rate was correlated independently. The resulting values of the kinetic parameters $v_{2}^{e}, v_{4}^{e}, \theta_{H}^{e}$ and $\alpha$ are shown in Table I. The theoretical dependence $j(\eta)$ obtained with these parameters are illustrated in Fig. 4a (continuous lines), showing the excellent capability of the proposed kinetic model for the description of the experimental response. Moreover, the parameters values informed in Table I correspond to individual fitting of markedly different curves, which led to similar values with a minimum deviation, as it can be appreciated in the last column. These kinetic parameters enable also the evaluation of the dependence $x_{H} / x_{H}^{e}(\eta)$ from Eq. 10, which is illustrated in Fig. 4b. It varies from 1 at equilibrium condition to 0 for $\eta>0.6 \mathrm{~V}$.
The dependence $\theta_{\mathrm{H}}(\eta)$ can also be simulated from Eq. 11, having the resulting curves a profile similar to those corresponding to $x_{H} / x_{H}^{e}(\eta)$.

The comparison of the equilibrium reaction rates with those obtained previously in acid solution gives similar values for the Heyrovsky step, while those of the Volmer step are significantly lower. ${ }^{16}$ This result shows how hydroxyl anion, not involved in acid solution, influences the oxidation of $\mathrm{H}_{\mathrm{ad}}$. It should be of interest to note that the consideration of equilibrium for steps (1) and (3) makes that the Tafel step,

$$
H_{2}+2 S \rightleftharpoons 2 H_{a d}
$$

should be also at equilibrium. However, steps (1) and (3) are processes that lead to the formation of $\mathrm{H}_{\mathrm{ad}}$ with an activation energy significantly less than that of the Tafel step. Therefore, this step can be considered negligible and the global reaction rate of the hor on Pd in alkaline solution is determined by the steps (1) and (3). This behavior is not verified in acid solution, where the increase of the rotation rate at constant overpotential produces a current increase. In this case, the reaction would take place through the TVH mechanism, with an important contribution of Tafel step. ${ }^{16}$ The direct absorption process (step 1) would not be feasible or significant. The concentration of $\mathrm{H}_{\mathrm{ab}}$ would be determined by the steady state surface coverage $\theta_{H}$, which depends of the simultaneous occurrence of the Tafel (16), Heyrovsky (2) and Volmer (4) steps, being the step (3) at equilibrium. On the other hand, in alkaline solution the kinetics is defined by the inhibition of Tafel step and the equilibrium of molecular hydrogen with $\mathrm{H}_{\mathrm{ab}}$ and $\mathrm{H}_{\mathrm{ad}}$. In this sense, the phase diagram of the system $\mathrm{H}_{2}-\mathrm{Pd}^{31}$ defines at $25^{\circ} \mathrm{C}$ and $P_{H_{2}}=1$ atm a solid phase that corresponds to $\beta \mathrm{Pd}-\mathrm{H}$. The equilibrium between $\alpha \mathrm{Pd}-\mathrm{H}$ and $\beta \mathrm{Pd}-\mathrm{H}$ is established at $P_{H_{2}}=0.014$ atm. Consequently, electrode remains as $\beta \mathrm{Pd}-\mathrm{H}$ from 1 atm (equilibrium) to 0.014 atm. Applying Eq. 9 and taking into account the Henry's law, ${ }^{4}$ the transition from $\beta \mathrm{Pd}-\mathrm{H}$ to $\alpha \mathrm{Pd}-\mathrm{H}$ is reached when the relationship $j / j_{L}=0.986$. Thus, in the range $0 \leq j / j_{L} \leq 0.986$ the hor is verified on $\beta \mathrm{Pd}-\mathrm{H}$ and the transition to $\alpha \mathrm{Pd}-\mathrm{H}$ cannot be detected because it is verified closed to the limiting diffusion current density. It can be also calculated from Eq. 10 the value of the relationship $x_{H} / x_{H}^{e}$ corresponding to the transition, which is equal to 0.118 . Therefore, the concentration of hydrogen in $\beta \mathrm{Pd}-\mathrm{H}$ varies in the range $1 \geq x_{H} / x_{H}^{e}$ $\geq 0.118$ (Fig. 4b). Finally, it should be noticed that the behavior described above cannot be discerned from the usual methodology based in the application of slow potentiodynamic sweeps (Fig. 3). This is basically due to the pseudocapacitive contributions that mask the current - potential response and is the reason why this behavior was not described previously.

\section{Conclusions}

The study of the steady state current - potential dependence of the hydrogen oxidation reaction on a thin film palladium electrode in alkaline solution showed a behavior not previously observed. The current density in the low overpotential region decreases when the electrode rotation rate is increased. This influence of the mass transport conditions on the response at low potentials, which could not be described by the Tafel-Heyrovsky-Volmer mechanism, was explained on the basis of a null or negligible contribution of the Tafel step, being replaced by a quick direct absorption of molecular hydrogen and the equilibrium between this and the adsorbed hydrogen. In this context, the experimental response could be adequately described through the Heyrovsky and Volmer steps. Finally, a comparative analysis of the Tafel step and the role played by the adsorbed hydrogen allowed the interpretation of the different behavior in both, acid and alkaline solutions.

\section{Acknowledgments}

This work was supported by Agencia Nacional de Promoción Científica y Tecnológica (ANPCyT, PICT 2014-2001), Consejo Nacional de Investigaciones Científicas y Técnicas (CONICET, PIP 
0311) and Universidad Nacional del Litoral (UNL, CAI+D 2016 PIC 018LI).

\section{Appendix: Derivation of Eqs. 5-8}

The reaction rates of steps (1-4) can be written as,

$$
\begin{gathered}
v_{1}=k_{1} C_{H_{2}}^{s}-k_{-1} x_{H}{ }^{2} \\
v_{2}=k_{2} C_{H_{2}}^{s} C_{O H^{-}}\left(1-\theta_{H}\right) e^{\alpha f E}-k_{-2} \theta_{H} e^{-(1-\alpha) f E} \\
v_{3}=k_{3}\left(1-\theta_{H}\right) x_{H}-k_{-3} \theta_{H} \\
v_{4}=k_{4} C_{O H^{-}} \theta_{H} e^{\alpha f E}-k_{-4}\left(1-\theta_{H}\right) e^{-(1-\alpha) f E}
\end{gathered}
$$

$k_{ \pm j}$ is the specific reaction rate constant of the step $j(j: 1-4)$ in the forward (+) and backward ( - ) direction. $\alpha$ is the symmetry factor, considered equal for the steps 2 and 4. Finally, $E$ is the potential referred to RHE in the same solution and $f=F / R T$. The corresponding reaction rates at equilibrium are,

$$
\begin{gathered}
v_{1}^{e}=k_{1} C_{H_{2}}^{o}=k_{-1} x_{H}^{e^{2}} \\
v_{2}^{e}=k_{2} C_{H_{2}}^{o} C_{O H^{-}}\left(1-\theta_{H}^{e}\right) e^{\alpha f E^{e}}=k_{-2} \theta_{H}^{e} e^{-(1-\alpha) f E^{e}} \\
v_{3}^{e}=k_{3}\left(1-\theta_{H}^{e}\right) x_{H}^{e}=k_{-3} \theta_{H}^{e} \\
v_{4}^{e}=k_{4} C_{O H^{-}} \theta_{H}^{e} e^{\alpha f E^{e}}=k_{-4}\left(1-\theta_{H}^{e}\right) e^{-(1-\alpha) f E^{e}}
\end{gathered}
$$

where the superscripts $e$ indicates equilibrium. Then, dividing the expressions A1-A4 by the corresponding A5-A8, Eqs. 5-8 are obtained.

\section{ORCID}

Abel C. Chialvo (D) https://orcid.org/0000-0002-1312-4921

\section{References}

1. J. X. Wang, S. R. Brankovic, Y. Zhu, J. C. Hanson, and R. R. Adzic, J. Electrochem. Soc., 150, A1108 (2003).

2. J. X. Wang, T. E. Springer, and R. R. Adzic, J. Electrochem. Soc., 153, A1732 (2006).

3. J. X. Wang, T. E. Springer, P. Liu, M. Shao, and R. R. Adzic, J. Phys. Chem. C, 111, 12425 (2007).

4. M. R. Gennero de Chialvo and A. C. Chialvo, Phys. Chem. Chem. Phys., 6, 4009 (2004).

5. P. M. Quaino, M. R. Gennero de Chialvo, and A. C. Chialvo, Electrochim. Acta, 52, 7396 (2007).

6. H. Frieske and E. Wicke, Ber. Bunsenges Phys. Chem., 77, 50 (1973).

7. S. Ramaprabhu, N. Rajalakshmi, and A. Weiss, Int. J. Hydrogen Energy, 23, 797 (1998).

8. T. Kuji, Y. Matsumura, H. Uchida, and T. Aizawa, J. Alloys Compd., 330-332, 718 (2002).

9. T. B. Flanagan and F. A. Lewis, Trans. Faraday Soc., 55, 1400 (1959).

10. I. Bakos, A. Paszternák, and D. Zitoun, Electrochim. Acta, 176, 1074 (2015).

11. S. M. Alia and Y. Yan, J. Electrochem. Soc., 162, F849 (2015).

12. W. Sheng, M. Myint, J. G. Chen, and Y. Yan, Energy Environ. Sci., 6, 1509 (2013).

13. J. Zheng, S. Zhou, S. Gu, B. Xu, and Y. Yan, J. Electrochem. Soc., 163, F499 (2016).

14. T. Bhowmik, M. Kumar Kundu, and S. Barman, ACS Catal., 6, 1929 (2016).

15. M. Alesker, M. Page, M. Shviro, Y. Paska, G. Gershinsky, D. R. Dekel, and D. Zitoun, J. Power Sources, 304, 332 (2016).

16. M. S. Rau, P. M. Quaino, M. R. Gennero de Chialvo, and A. C. Chialvo, Electrochem. Commun., 10, 208 (2008).

17. S. Schuldiner, G. W. Castellan, and J. P. Hoare, J. Chem. Phys., 28, 16 (1958).

18. R. J. Ratchford and G. W. Castellan, J. Phys. Chem., 62, 1123 (1958)

19. A. Lasia and D. Gregoire, J. Electrochem. Soc., 142, 3393 (1995).

20. A. Lasia, J. Electroanal. Chem., 593, 159 (2006).

21. M. H. Martin and A. Lasia, Electrochim. Acta, 53, 6317 (2008).

22. M. H. Martin and A. Lasia, Electrochim. Acta, 54, 5292 (2009).

23. D. Lin and A. Lasia, J. Electroanal. Chem., 785, 190 (2017).

24. J. O'M. Bockris, J. McBreen, and L. Nanis, J. Electrochem. Soc., 112, 1025 (1965).

25. C. Lim and S. I. Pyun, Electrochim. Acta, 39, 363 (1994).

26. G. Zheng, B. N. Popov, and R. E. White, J. Electrochem. Soc., 142, 154 (1995).

27. M. A. Montero, M. R. Gennero de Chialvo, and A. C. Chialvo, J. Electroanal. Chem., 767, 153 (2016).

28. M. A. Montero, M. R. Gennero de Chialvo, and A. C. Chialvo, J. Power Sources, 283, 181 (2015).

29. L. Fang, Q. Tao, M. Li, L. Liao, D. Chen, and Y. Chen, Chin. J. Chem. Phys., 23, 543 (2010).

30. K. Hubkowska, M. Soszko, M. Symonowicz, M. Łukaszewski, and A. Czerwinski, Electrocatalysis, 8, 295 (2017).

31. J. W. Simons and T. B. Flanagan, J. Phys. Chem., 69, 3773 (1965). 